
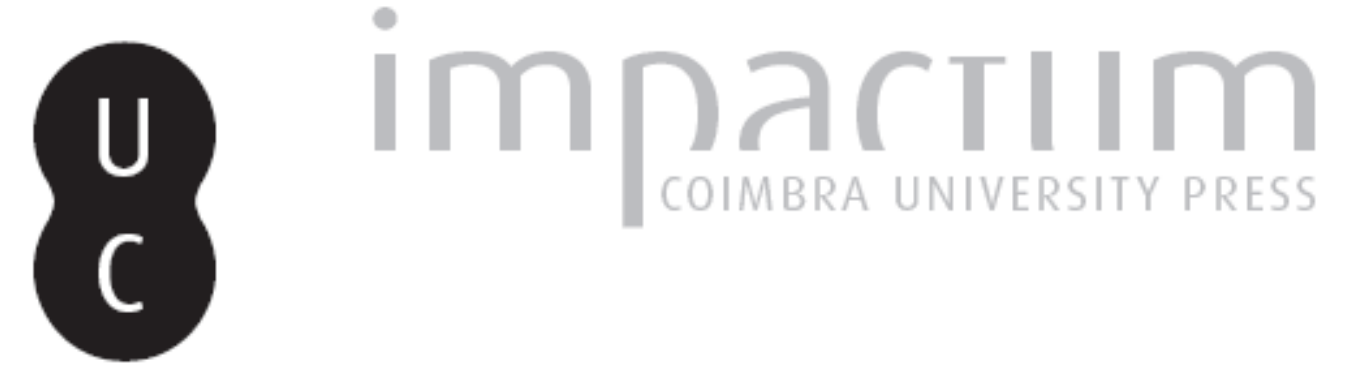

\title{
Três estatuetas funerárias egípcias na Fundação Medeiros e Almeida
}

Autor(es): $\quad$ Silva, Andreia Cunha da; Araújo, Luís Manuel de

Publicado por: Centro de História da Universidade de Lisboa

URL persistente:

URI:http://hdl.handle.net/10316.2/34983

DOI:

DOI:http://dx.doi.org/10.14195/0871-9527_23_4

Accessed : $\quad$ 26-Apr-2023 13:54:31

A navegação consulta e descarregamento dos títulos inseridos nas Bibliotecas Digitais UC Digitalis, UC Pombalina e UC Impactum, pressupõem a aceitação plena e sem reservas dos Termos e Condições de Uso destas Bibliotecas Digitais, disponíveis em https://digitalis.uc.pt/pt-pt/termos.

Conforme exposto nos referidos Termos e Condições de Uso, o descarregamento de títulos de acesso restrito requer uma licença válida de autorização devendo o utilizador aceder ao(s) documento(s) a partir de um endereço de IP da instituição detentora da supramencionada licença.

Ao utilizador é apenas permitido o descarregamento para uso pessoal, pelo que o emprego do(s) título(s) descarregado(s) para outro fim, designadamente comercial, carece de autorização do respetivo autor ou editor da obra.

Na medida em que todas as obras da UC Digitalis se encontram protegidas pelo Código do Direito de Autor e Direitos Conexos e demais legislação aplicável, toda a cópia, parcial ou total, deste documento, nos casos em que é legalmente admitida, deverá conter ou fazer-se acompanhar por este aviso.

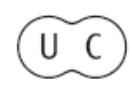



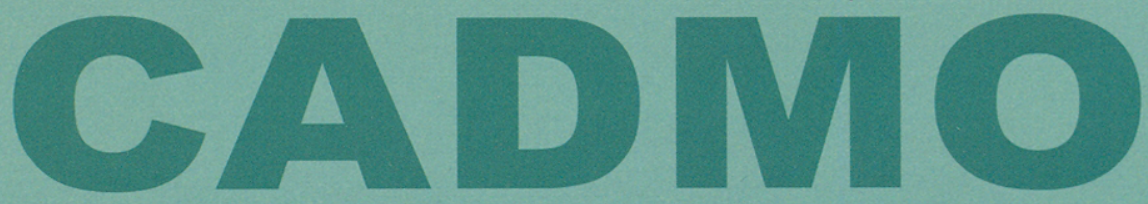

Revista de História Antiga

\author{
Centro de História \\ da Universidade de Lisboa
}

\title{
23
}

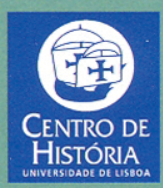

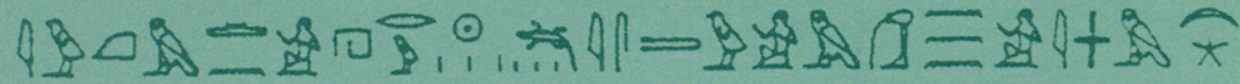

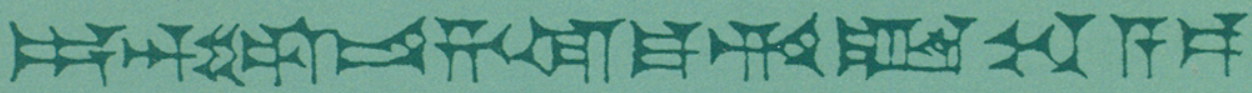
MHNIN AEI $\triangle \mathrm{E} \Theta \mathrm{EA}$ ПH$\Lambda \mathrm{HIA} \triangle \mathrm{E} \Omega$ 


\title{
TRÊS ESTATUETAS FUNERÁRIAS EGÍPCIAS NA FUNDAÇÃO MEDEIROS E ALMEIDA
}

\author{
ANDREIA CUNHA DA SILVA \\ andreia.silva.c@gmail.com \\ LUÍS MANUEL DE ARAÚJO \\ Universidade de Lisboa \\ luisaraujo@fl.ul.pt
}

Recentemente tivemos conhecimento de mais uma pequena coleção egípcia, apenas com três objetos, existente na Casa-Museu Medeiros e Almeida (1), que integra a Fundação do mesmo nome, situada na Rua Rosa Araújo, em Lisboa, num elegante palacete dos finais do século XIX, onde já funcionou, nos anos 30 do século passado, a Nunciatura Apostólica do Vaticano. O grande imóvel viria a ser adquirido por António Medeiros e Almeida em 1943, que lá se instalou em 1947, ali vivendo durante muitos anos.

Depois de uma breve passagem pela Universidade de Coimbra, onde não chegou a concluir o seu curso de Medicina, preferiu António Medeiros e Almeida estudar Gestão e Contabilidade na Alemanha no início dos anos vinte do século passado. Iniciou-se depois no mundo dos negócios, dedicando-se à atividade empresarial com grande sucesso, e por isso veio a ser um dos homens mais ricos de Portugal, tendo em suas mãos a administração de duas dezenas de empresas. O dinâmico empresário, dispondo dos fartos lucros dos seus negócios, começou em 1925 a sua coleção de arte, reunindo objetos variados de diferentes épocas e espaços mundiais, e em 1956 foi o seu acervo de antiguidades 
aumentado com a integração das três estatuetas funerárias egípcias que aqui se apresentam, as quais foram oferecidas ao colecionador pela firma Soares \& Mendonça Lda., uma agência de leilões e de avaliações de objetos de arte, fundada em 1937, e da qual António Medeiros e Almeida era assíduo cliente.

Já idoso e sem filhos, decidiu o empresário criar, em 1973, uma fundação, à qual doou todos os seus bens, incluindo a sua enorme coleção que recheava a casa onde vivia, maioritariamente constituida por objetos artísticos reunidos ao longo de cinquenta anos, o que o levou a fazer investimentos de vulto e a viajar por vários países na busca das peças que mais Ihe interessavam ${ }^{(2)}$. O espólio da Fundação, grande parte do qual se encontra exposto na Casa-Museu Medeiros e Almeida, é muito rico e heterogéneo, ocupando dois pisos da casa, sendo de destacar que no primeiro piso se encontra uma coleção de relógios considerada uma das mais valiosas da Europa. Quanto aos três objetos egípcios que aqui se descrevem, eles não se encontram expostos ${ }^{(3)}$.

Trata-se de três estatuetas funerárias de faiança esverdeada, que podem ser datadas da XXX dinastia (380-343 a. C.) ou inícios da subsequente Época Greco-romana (dinastia ptolemaica). Os traços do rosto das figurinhas evidenciam o típico «sorriso saíta» em uso na Época Baixa com a XXVI dinastia (664-525 a. C.), cuja capital era em Sais, cidade do Delta ocidental (dai a designação de dinastia saíta que amiúde se utiliza para este período de alguma estabilidade política). Este termo estende-se ao «sorriso saíta», que as imagens desse tempo exibem, feitos com maior ou menor trejeito, e que continuou a ser sugerido nos rostos de imagens das dinastias seguintes, prolongando-se em algumas figurinhas da dinastia ptolemaica ${ }^{(4)}$.

Outra característica das estatuetas funerárias da Época Baixa, e que iria continuar pela dinastia ptolemaica, é o uso de uma pêra divina no queixo atestando a assimilação das figuras a Osíris, deus da eternidade, com quem os defuntos se identificavam para a fruição da outra vida ${ }^{(5)}$, e a inclusão de um pilar dorsal que assenta numa base retangular, ou por vezes quadrada, que aparecem também na Época Baixa ${ }^{(6)}$. Há ainda outra novidade nas estatuetas funerárias desta época: o aparecimento de inscrições hieroglíficas dispostas em forma de $T$ na parte frontal, e duas das figurinhas apresentam o texto em $\mathrm{T}^{(7)}$.

As estatuetas funerárias apareceram durante o Império Médio (c. 2000 a. C.), com um aspeto um tanto fruste, mas depois tornaram-se 
presença obrigatória nos túmulos dos funcionários. Os reis só viriam a usar as figurinhas a partir do Império Novo, começando com Ahmés ${ }^{(8)}$, o fundador da XVIII dinastia (cerca de 1550 a. C.), e assim os poderosos faraós passaram também a ter ao seu serviço, para os trabalhos no outro mundo, as suas próprias estatuetas funerárias ${ }^{(9)}$. A elas se dá o nome de chauabtis, forma que deriva da palavra chauab, a qual se referia à árvore persea e à sua madeira, se bem que os materiais utilizados pudessem variar: pedra, faiança, bronze ou terracota (que podia ser vitrificada na superfície). A partir da XXI dinastia (Terceiro Período Intermediário) elas passaram a ser chamadas uchebtis, a partir do verbo $u c h e b$, «responder», porque se entendeu então que o papel da estatueta seria responder em lugar do defunto quando este fosse chamado para trabalhar nos campos do Além. Por isso se designam por uchebtis as estatuetas da Época Baixa, geralmente feitas de faiança azul ou verde, com diferentes tonalidades, e por vezes com inscrições, como é o caso das três que neste artigo divulgamos ${ }^{(10)}$.

\section{1 - Estatueta funerária anepígrafa}

Dimensões: Alt.: 12,4 cm; larg.: 3,4 cm. № inv.: 1779

Figura mumiforme anepígrafa de faiança esverdeada, com o corpo bem torneado e as mãos saindo do envoltório fúnebre para segurar os

Estatueta funerária (uchebti) anepígrafa de faiança esverdeada (frente e costas, vendo-se o pilar dorsal ainda com o número atribuido pelo colecionador).
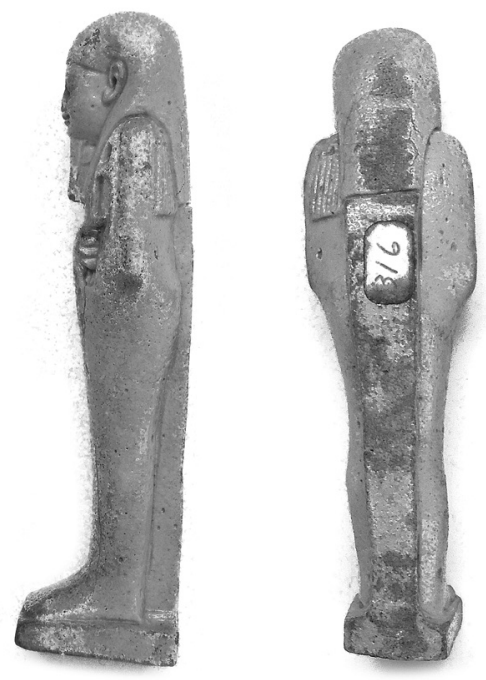
instrumentos agrícolas. O rosto tem bons detalhes em relevo, com os olhos, o nariz e as orelhas bem assinalados, e os lábios a esboçarem um ligeiro sorriso, tendo no queixo a tradicional pêra osírica encorpada. O rosto arredondado é envolvido por uma cabeleira lisa tripartida, caindo duas partes sobre o peito e outra sobre as costas. Na mão esquerda exibe um sacho e na direita um alvião e a corda do cesto das sementes que cai sobre o ombro esquerdo. Atrás tem o habitual pilar dorsal, que começa no final da cabeleira e vai até à base retangular ${ }^{(11)}$.

\section{2 - Estatueta funerária com nome ilegível}

Dimensões: Alt.: 9,9 cm; larg.: 2,6 cm. Nº inv.: 1780

Figura mumiforme de faiança esverdeada, com o corpo razoavelmente modelado, partida pelos joelhos e colada, com as mãos saindo do envoltório fúnebre para segurar os instrumentos agrícolas. O rosto tem detalhes em relevo, com os olhos, o nariz e as orelhas bem assinalados, e os lábios a esboçarem um ligeiro sorriso (mas não tão percetível como a anterior figura), tendo no queixo a tradicional pêra osírica encorpada. O rosto é envolvido por uma cabeleira lisa tripartida, caindo duas partes sobre o peito e outra sobre as costas. Na mão esquerda exibe um sacho e na direita um alvião e a corda do cesto das sementes que cai sobre o ombro esquerdo. Atrás tem o habitual pilar dorsal, que começa no final da cabeleira e vai estreitanto ligeiramente até à base retangular. Na parte frontal apresenta um texto hieroglífico disposto em $\mathrm{T}$, estando os textos na horizontal e na vertical delimitados por traços incisos. Infelizmente não é possível dar o nome correto do proprietário porque a leitura é, por agora, ilegível, podendo o nome da mãe ser Neferibhor ${ }^{(12)}$.

Inscrição hieroglífica em T:

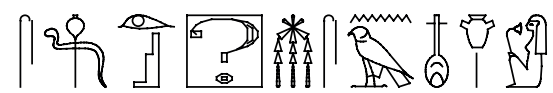

Tradução: «Que brilhe o Osíris (?), filho de Neferibhor». 


\section{3 - Estatueta funerária com nome ilegível}

Dimensões: Alt.: 8,4 cm; larg.: 2,3 cm. No inv.: 1781

Figura mumiforme de faiança esverdeada, com o corpo razoavelmente modelado, partida pelos tornozelos, não tendo por isso a base original. As mãos saem do envoltório fúnebre para segurar os instrumentos agrícolas. $O$ rosto tem detalhes em relevo, com os olhos, o nariz e as orelhas bem assinalados, e os lábios a esboçarem um apagado sorriso, tendo no queixo a tradicional pêra osírica encorpada. O rosto é envolvido pela cabeleira lisa tripartida, caindo duas partes sobre o peito e outra sobre as costas. Na mão esquerda exibe um sacho e na direita um alvião e a corda do cesto das sementes que cai sobre o ombro esquerdo. Atrás tem o habitual pilar dorsal, que começa no final da cabeleira e vai estreitanto ligeiramente, terminando antes da base que desapareceu. Tal como na figura anterior, tem na parte frontal um texto hieroglífico disposto em T, estando os textos na horizontal e na vertical delimitados por traços incisos. Infelizmente não é possível dar o nome correto do proprietário porque a leitura é, por agora, ilegível, podendo o nome da mãe ser Neferibhor.

Inscrição hieroglífica em T:

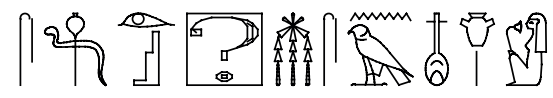

Tradução: «Que brilhe o Osíris (?), filho de Neferibhor».

Estatuetas funerárias (uchebtis) de um funcionário com nome ilegivel, estando uma delas fraturada pelos joelhos e outra já sem a base.
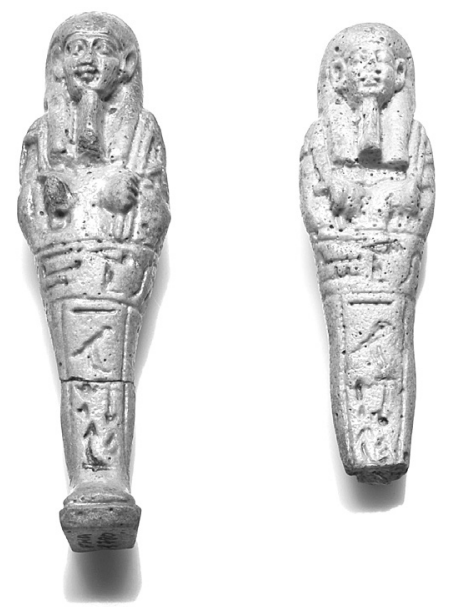


\section{Notas}

(1) Um agradecimento é devido a Paulo Emiliano, designer na Fundação Calouste Gulbenkian e membro da direção da Associação Cultural de Amizade Portugal-Egipto, por ter facilitado o contacto com a direção do Museu, sendo também necessário agradecer o eficaz apoio recebido da diretora, Dra Teresa Vilaça, e de suas colaboradoras. Merece ainda ser reconhecido com gratidão o atempado envio das imagens das estatuetas por Samantha Coleman.

(2) Não deixa de ser tentador comparar a atividade de colecionador e admirador de objetos de arte que tornou António Medeiros e Almeida conhecido no seu meio com o percurso de Calouste Gulbenkian, que também criou uma notável fundação com o seu nome, à qual pertence um museu com inúmeras obras de arte de alta qualidade (incluindo um acervo egípcio de relevo).

(3) Esta situação ocorreu também com a pequena coleção egípcia do Museu Nacional de Soares dos Reis, no Porto, que possui oito objetos provenientes da antiga coleção John Allen. Pertence a este pequeno acervo a melhor estatueta funerária de faiança existente no nosso país, com o nome de Djedhor. Depois de ter sido reconhecida a valia de alguns dos objetos foi o pequeno núcleo exposto (ver ARAÚJO, «A colecção egípcia do Museu Nacional de Soares dos Reis», pp. 7-20).

(4) Foi na XXX dinastia que se acentuou a produção de figurinhas com o texto disposto em T, embora a opção tenha surgido antes. Um significativo exemplo em SCHLÖGL, Uschebti, pp. 52-53: trata-se neste caso de uma estatueta funerária com texto em T que os autores atribuem à derradeira XXX dinastia ou a inícios da dinastia ptolemaica (séculos IV-III a. C.), exibindo na inscrição hieroglífica o nome de Uennefer, filho de Nekhbetnen (cf. AUBERT, Statuettes Égyptiennes, p. 243). Quanto ao "sorriso saíta» representado nas três figurinhas que aqui se divulgam não é tão expressivo como outros que se observam em rostos desse período, os quais têm sugestivos exemplos numa estatueta de bronze do deus Osíris da coleção egípcia do Museu Calouste Gulbenkian, ou o da dama Chepés, do mesmo acervo (ver ARAÚJO, Arte Egípcia, p. 115 (Osíris) e p. 117 (dama Chepés).

(5) Ver ARAÚJO, Arte Egípcia, p. 115 (Osíris); também com exemplo na coleção egípcia do Museu Nacional de Arqueologia, em ID., Antiguidades Egipcias, p. 222, fig. 137 (estatueta funerária de Horimhotep, com a pêra entrançada e texto em T).

(6) Ver STEWART, Egyptian Shabtis, pp. 30-31; também em ARAÚJO, Estatuetas Funerárias Egípcias da XXI Dinastia, p. 152.

(7) Para o aparecimento dos textos dispostos em T ver AUBERT, Statuettes Égyptiennes, p. 243. O mais antigo uchebti conhecido com texto em T pertenceu ao sacerdote Ahmés e data da XXVII dinastia persa, constituída por reis aqueménidas, mais precisamente do reinado de Dário I (522-486 a. C.). Outro exemplar da mesma época foi feito para o general Psametek-meriamon, existindo vários da XXX dinastia com o texto em T nas pp. 249-263. No anexo de imagens constam, na pl. 63, três uchebtis pertencentes ao general Psametek-meriamon (149), a Djedhor, filho de Renpetnefer (150) e ao escriba real Nesochitefnut (151).

(8) Ver AUBERT, Statuettes Égyptiennes, p. 26; ver também ARAÚJO, Estatuetas Funerárias Egípcias da XXI Dinastia, pp. 135-136.

(9) As estatuetas iriam trabalhar nos campos do Além, e por isso iam providas de instrumentos agrícolas que na Época Baixa eram geralmente o sacho e o alvião mais um saco de sementes representado atrás e com uma corda que é segurada por uma das mãos, como se vê nas estatuetas deste pequeno acervo. Nestes três casos a corda é segurada pela mão direita, caindo o saco sobre o ombro esquerdo, sendo ainda de notar que nos três casos as mãos têm os polegares saídos.

${ }^{(10)}$ A partir da XXI dinastia os chauabtis passaram a ser designados por uchebtis, porque se entendeu então que o papel da estatueta era responder em lugar do defunto quando este fosse chamado para «trabalhar» nos campos do Além. Além disso, a partir do Terceiro Período Intermediário 
a faiança tornou-se o material mais usado. Quanto ao número de exemplares por proprietário, foram achados túmulos com 365 estatuetas, para que em cada dia do ano «trabalhasse» uma das figurinhas. Além dos túmulos reais, também em túmulos de particulares apareceu por vezes um número considerável de estatuetas, as quais eram guardadas em caixas especiais de madeira pintada onde figurava o nome e os títulos do defunto. A Época Baixa, que se iniciou com a XXVI dinastia saíta, evidencia-se pelas suas belas estatuetas de faiança azul ou verde, com diferentes tonalidades, mas ela não é mais que um «período de cristalização» das formas e dos costumes de épocas anteriores, aparecendo contudo novos detalhes na modelação: o pequena base em forma de pedestal, o pilar dorsal, a pêra osírica (por vezes entrançada) e o curioso «sorriso saíta" que continuou timidamente na dinastia ptolemaica (ver ARAÚJO, Estatuetas Funerárias Egípcias da XXI Dinastia, pp. 150-153).

${ }^{(11)}$ Por vezes o próprio pilar dorsal das estatuetas exibe uma inscrição hieroglífica na vertical, o que não sucede com os exemplares que aqui apreciamos.

${ }^{(12)} \mathrm{O}$ nome da mãe do anónimo prorietário da estatueta parece ser Neferibhor, cuja tradução é «É belo o coração de Hórus». Se a tradução do nome estiver certa, ele evoca um dos mais conhecidos deuses egípcios venerados desde tempos imemoriais, estando este nome construído com recurso à anteposição honorífica do nome Hor, como sucede com outro nome muito típico da Época Baixa, Neferibré («É belo o coração de Ré»).

\section{Bibliografia}

Luís Manuel de ARAÚJO, Antiguidades Egípcias, Museu Nacional de Arqueologia, Lisboa: Instituto Português de Museus, 1993.

Luís Manuel de ARAÚJO, «A colecção egípcia do Museu Nacional de Soares dos Reis», em Museu, 3, IV série, Porto: Museu Nacional de Soares dos Reis, 1995, pp. 7-20.

Luís Manuel de ARAÚJO, «Estatuetas funerárias», em Dicionário do Antigo Egipto, Lisboa: Editorial Caminho, 2001, pp. 344-346.

Luís Manuel de ARAÚJO, Estatuetas Funerárias Egípcias da XXI dinastia, Lisboa: Fundação Calouste Gulbenkian e Fundação para a Ciência e a Tecnologia, 2003.

Luís Manuel de ARAÚJO, Arte Egípcia, Museu Calouste Gulbenkian, Lisboa: Fundação Calouste Gulbenkian, 2006.

J.-F. AUBERT e Liliane AUBERT, Statuettes Égyptiennes. Chaouabtis, ouchebtis, Paris: Librairie d'Amérique et d'Orient Adrien Maisonneuve, 1974.

Hans D. SCHNEIDER, Shabtis. An Introduction to the History of Ancient Egyptian Funerary Statuettes with a Catalogue of the Collection of Shabtis in the National Museum of Antiquities at Leiden, I-III, Leiden: Rijksmuseum van Oudheden te Leiden, 1987.

Hermann A. SCHLÖGL e Christa-Meves SCHLÖGL, Uschebti, Arbeiter im ägyptischen Totenreich, Wiesbaden: Otto Harrassowitz, 1993.

Harry M. STEWART, Egyptian Shabtis, Shire Egyptology, 23, Princes Risborough: Shire Publications, 1995. 